\title{
Association between inflammatory biomarkers and adiposity in obese patients with heart failure and metabolic syndrome
}

\author{
MARJAN MOTIE ${ }^{1}$, LORRAINE S. EVANGELISTA ${ }^{1}$, TAMARA HORWICH ${ }^{2}$, DAWN LOMBARDO ${ }^{3}$, \\ FRANK ZALDIVAR ${ }^{4}$, MICHELE HAMILTON ${ }^{5}$ and GREGG C. FONAROW ${ }^{2}$ \\ ${ }^{1}$ Program of Nursing Science, University of California Irvine, Irvine, CA 92697; ${ }^{2}$ Division of Cardiology, \\ David Geffen School of Medicine, University of California at Los Angeles, Los Angeles 90095, CA; \\ ${ }^{3}$ Division of Cardiology, Department of Medicine, University of California Irvine Medical Center, Orange 92868, CA; \\ ${ }^{4}$ Institute for Clinical and Translational Science, University of California Irvine Medical Center, \\ Orange 92868, CA; ${ }^{5}$ Cedars-Sinai Heart Institute, Los Angeles 90048, CA, USA
}

Received November 14, 2013; Accepted March 31, 2014

DOI: 10.3892/etm.2014.1673

\begin{abstract}
Obesity, type 2 diabetes mellitus (DM) and metabolic syndrome (MS) are common in patients with heart failure (HF). Studies investigating the association between known biomarkers and adiposity in patient populations are limited. The aim of the present study was to investigate the association between $\mathrm{C}$-reactive protein (CRP) and leptin with adiposity in a sub-group of overweight/obese patients with HF, DM and/or MS. A total of 36 patients (mean age, 56.72 \pm 9.78 years; ranging between 27 and 76 years of age; $80.6 \%$ male; $52.8 \%$ Caucasian) were enrolled and their height, weight, waist circumference and body composition (e.g. percentage body fat and lean mass), as well as the levels of CRP and leptin, were assessed. The results demonstrated that there was a significant association between CRP and leptin, CRP and body mass index (BMI) and gender and percentage body fat $(\mathrm{P}<0.05$, for all associations). Analysis of leptin and CRP levels revealed that patients in the highest BMI quartile (BMI, 40.3-61.2) had higher CRP levels $(4.83 \mu \mathrm{g} / \mathrm{ml}$ vs. $3.03 \mu \mathrm{g} / \mathrm{ml} ; \mathrm{P}=0.033)$ and higher leptin levels $(44.97 \mathrm{ng} / \mathrm{ml}$ vs. $24.64 \mathrm{ng} / \mathrm{ml} ; \mathrm{P}=0.042)$ compared with patients in the lower BMI quartile (BMI, 28.6-32.4). In conclusion, among obese patients with HF, DM and/or MS, an association between CRP and leptin was identified, providing further evidence that metabolic and inflammatory mechanisms are involved in these diseases. Future investigation to assess the potential impact of inflammation and adiposity, and the role of dietary interventions and weight loss on clinical outcomes in this population of chronically ill patients is warranted.
\end{abstract}

Correspondence to: Dr Marjan Motie, Program of Nursing Science, University of California Irvine, Irvine, CA 92697, USA E-mail:mmotie@uci.edu; marjan_motie@hotmail.com

Key words: heart failure, biomarkers, C-reactive protein, leptin, obesity

\section{Introduction}

Heart failure (HF), obesity and type 2 diabetes mellitus (DM) are disease conditions associated with the progression of cardiovascular disease, functional disability and a diminished quality of life as reported in our recent study (1). Previous studies have also indicated that the coexistence of all three conditions leads to the combined synergistic interaction of pathophysiological responses associated with each condition resulting in a higher morbidity and mortality rate (2-7). Numerous contributing factors have been hypothesized to be involved in obesity-linked metabolic and inflammatory alterations associated with cardiovascular disease. Two of these factors that have been implicated in each of these disease states are $\mathrm{C}$-reactive protein (CRP) and leptin.

CRP is a marker of systemic inflammation and the levels of CRP markedly increase as part of the acute-phase response. CRP is synthesized by the liver and regulated by cytokines, particularly interleukin (IL)-6 (7). Elevated levels of CRP have been found to be associated with the development of coronary heart disease and metabolic syndrome (MS) (8-11). Current evidence suggests that inflammation and biomarkers, including high-sensitivity CRP, may be as important as cholesterol in determining the development of atherosclerosis and heart disease. By contrast, whilst obesity is one of the strongest determinants of CRP levels (12), the exact mechanism linking obesity and inflammation remains to be elucidated.

Leptin, an adipocyte-derived hormone is involved in appetite regulation, insulin homeostasis and obesity through the effects of the hypothalamus $(13,14)$. Leptin levels may be used to predict the development of MS independent of obesity (15). Furthermore, leptin has also been implicated in contributing to an increased risk of cardiovascular disease with or without coexisting atherosclerosis (16-18). It has been proposed that leptin may induce the expression of CRP in vascular endothelial cells leading to possible deleterious effects (19). This theory is supported by studies reporting a significant correlation between levels of leptin and CRP in a variety of patient populations (20-25). A number of studies have also investigated the involvement of CRP in 'leptin resistance' 
(the coexistence of elevated leptin levels in obese individuals despite the role of leptin in decreasing appetite and reducing food intake) (26-28). There are, however, clear gaps in the understanding of the correlation between leptin and CRP in terms of whether leptin affects CRP expression directly or through independent mechanisms, and to what extent the interactions directly affect the onset and course of disease.

The aim of the present study was to determine the circulating levels of CRP and leptin and to examine their correlation with each other as well as with body mass index (BMI) and adiposity in overweight/obese patients with HF, DM and/or MS. Investigation of these biomarkers may provide insight into the association between inflammatory and metabolic mechanisms involved in disease onset and pathophysiology in this patient population.

\section{Patients and methods}

Study population. A total of 36 subjects (>18 years old) were recruited and provided informed consent to participate in a randomized controlled clinical trial for overweight/obese patients with HF, DM and/or MS. The present study was approved by the Institutional Human Subjects Review Committee. Inclusion criteria included a BMI >27, New York Heart Association (NYHA) functional class II or III HF (either with preserved left ventricular ejection fraction $[\mathrm{HFpEF}]$ or reduced ejection fraction $[\mathrm{HFrEF}])$ and a history of DM (e.g. impaired fasting glucose of 100-125 mg/dl), or meeting three or more of the criteria for MS. Participants were excluded if they were pregnant, had a serum creatinine level $>1.5 \mathrm{mg} / \mathrm{dl}$ or had a history of clinically significant illness, including acute myocardial infarction or sustained ventricular arrhythmia three months prior to the start of the experiment. In addition, patients were also excluded if they were currently suffering from liver, respiratory and/or gastrointestinal disease and malignancy, or a history of gout. Participants were interviewed by nurses to provide information regarding sociodemographic and clinical variables (including, age, gender, history of illness and medication).

Weight, BMI and waist circumference. Height, weight, waist circumference and vital signs were measured by the research staff as previously described (1). Body composition was measured by having participants complete a whole-body scan with dual-energy X-ray absorptiometry (Hologic 4500A, version 12.3; Hologic, Inc., Waltham, MA, USA), which provided assessments of fat, lean and bone mineral mass by measuring the differential absorption of X-rays and utilizing the computer algorithms provided by the manufacturer. Percentage body fat was calculated as the ratio of fat mass relative to overall body weight.

Laboratory measurements. Following an overnight fast, venous blood samples were obtained and the levels of total cholesterol, high-density lipoprotein, low-density lipoprotein, triglycerides, fasting blood glucose and insulin were measured. High sensitivity CRP and leptin levels were measured using Quantikine Elisa Assay kits purchased from R\&D Systems (Minneapolis, MN, USA). CRP was measured with lower and upper detection limits of $0.78 \mathrm{ng} / \mathrm{ml}$ and $50 \mathrm{ng} / \mathrm{ml}$, respectively, using an assay sensitivity of $0.022 \mathrm{ng} / \mathrm{ml}$. The assay for leptin measured between 16 and $1,000 \mathrm{pg} / \mathrm{ml}$, with a sensitivity of $7.8 \mathrm{pg} / \mathrm{ml}$.

Statistical analysis. Patients were classified into four BMI $\left(\mathrm{kg} / \mathrm{m}^{2}\right)$ categories based on quartiles of all BMI data collected in the present study: i) BMI 28.6-32.4, ii) BMI 32.5-35.8, iii) BMI 35.9-40.2 and iv) BMI 40.3-61.2. Data were analyzed using SPSS statistical software version 19.0 for Windows (SPSS, Inc., Chicago, IL, USA). Analysis of variance was used to compare sociodemographic and clinical variables of the entire sample size $(n=36)$, as well as each of the BMI quartiles. Comparison of CRP and leptin levels within gender or BMI groups was performed using the independent samples t-test. The association between serum CRP and leptin levels and age, gender, waist circumference, total percentage fat and total cholesterol were evaluated using Pearson's product moment correlation coefficient and Spearman's Rho, depending on the level of measurement. Multivariate analysis was performed to test the independent association between CRP and leptin using leptin as the dependent variable and CRP, age, gender, BMI, waist circumference and statin as covariates.

\section{Results}

Participant characteristics. Table I shows the sociodemographic and clinical characteristics of the study sample. Comparative data for the four BMI quartiles are also illustrated in the table. Participants ranged between 27 and 77 years old (average age, 56.72 \pm 9.8 years), and were predominantly male $(80.6 \%)$. On average, participants were moderately obese (weight, $113.78 \pm 25.57 \mathrm{~kg}$; BMI $37.6 \pm 7.2 \mathrm{~kg} / \mathrm{m}^{2}$ ) and had a mean total cholesterol of $158.5 \pm 39.6$ and a total body fat percentage of $36.9 \pm 7.0 \%$. With the exception of the expected weight-associated variables (weight, BMI and waist circumference), the participants in the four BMI quartiles only differed significantly in the mean age (due to the inclusion of a 27 year old in the highest quartile).

Association between CRP and leptin and other cardiovascular risk factors. Univariate analyses for variables of interest are illustrated in Table II. BMI was associated with age $(\mathrm{P}=0.001)$ and CRP $(\mathrm{P}=0.043)$. The association between $\mathrm{BMI}$ and age is an outcome of significantly lower mean age in the highest BMI quartile (Table I) compared with all the other BMI quartiles. A strong correlation between CRP and leptin was also observed $(\mathrm{P}=0.001)$. In the multivariate analysis, leptin was independently associated with CRP, following adjustment for age, gender, BMI, waist circumference and whether or not the patient was using lipid lowering statin drugs $(\mathrm{F}=1.05 ; \mathrm{P}=0.002)$. A statistically significant correlation between gender and total body fat $(\mathrm{P}<0.001)$ and $\mathrm{CRP}(\mathrm{P}=0.02)$ was identified. Gender differences between CRP, leptin and percentage body fat are illustrated in Table III. Females had significantly higher levels of CRP and percentage body fat compared with males.

The different BMI quartiles were then compared in order to further evaluate the association between obesity and levels of CRP and leptin. While the association between leptin and CRP was independent of obesity level, there was a statistically significant increase in the concentration of these markers as 
Table I. Sociodemographic and clinical characteristics $(n=36)$.

\begin{tabular}{|c|c|c|c|c|c|c|}
\hline \multirow[b]{2}{*}{ Characteristic } & \multirow[b]{2}{*}{$\begin{array}{l}\text { All participants } \\
\qquad(\mathrm{n}=36)\end{array}$} & \multicolumn{3}{|c|}{ BMI quartile } & \multirow[b]{2}{*}{$\begin{array}{c}\text { (iv) } \begin{array}{c}40.3-61.2 \\
(\mathrm{n}=9)\end{array}\end{array}$} & \multirow[b]{2}{*}{ P-value } \\
\hline & & $\begin{array}{c}\text { (i) } 28.6-32.4 \\
(\mathrm{n}=9)\end{array}$ & $\begin{array}{c}\text { (ii) } \begin{array}{c}32.5-35.8 \\
(\mathrm{n}=10)\end{array}\end{array}$ & 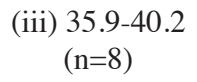 & & \\
\hline Age, (years) & $56.72 \pm 9.78$ & $60.78 \pm 6.61$ & $57.90 \pm 5.11$ & $60.00 \pm 11.08$ & $48.44 \pm 11.40$ & 0.021 \\
\hline Male, n (\%) & $29(80.6 \%)$ & $8(88.9 \%)$ & $8(80.0 \%)$ & $7(87.5 \%)$ & $5(55.6 \%)$ & 0.298 \\
\hline Diastolic blood pressure $(\mathrm{mmHg})$ & $73.14 \pm 13.23$ & $74.56 \pm 13.36$ & $66.80 \pm 6.39$ & $70.25 \pm 15.31$ & $81.33 \pm 14.13$ & 0.095 \\
\hline Systolic blood pressure $(\mathrm{mmHg})$ & $120.72 \pm 23.84$ & $120.44 \pm 14.98$ & $105.50 \pm 14.20$ & $126.00 \pm 34.28$ & $133.22 \pm 22.64$ & 0.066 \\
\hline Patient taking statins $(\%)$ & $27(75.0 \%)$ & $7(77.8 \%)$ & $8(80.0 \%)$ & $8(100 \%)$ & $4(44.4 \%)$ & 0.062 \\
\hline Weight $(\mathrm{kg})$ & $113.78 \pm 25.57$ & $96.87 \pm 7.41$ & $101.99 \pm 10.88$ & $108.10 \pm 10.90$ & $145.61 \pm 26.85$ & $<0.001$ \\
\hline $\mathrm{BMI}\left(\mathrm{kg} / \mathrm{m}^{2}\right)$ & $37.64 \pm 7.24$ & $30.90 \pm 1.21$ & $34.43 \pm 1.13$ & $37.40 \pm 1.69$ & $48.15 \pm 5.95$ & $<0.001$ \\
\hline Waist circumference $(\mathrm{cm})$ & $47.41 \pm 4.84$ & $43.61 \pm 2.89$ & $45.92 \pm 2.26$ & $47.44 \pm 3.80$ & $53.18 \pm 3.77$ & $<0.001$ \\
\hline Total \% fat (DEXA) & $36.88 \pm 6.98$ & $30.52 \pm 4.42$ & $35.17 \pm 6.53$ & $38.62 \pm 3.54$ & $44.42 \pm 4.72$ & $<0.001$ \\
\hline Fasting glucose (mg/dl) & $130.09 \pm 51.29$ & $110.67 \pm 22.45$ & $156.60 \pm 50.66$ & $133.78 \pm 73.04$ & $130.34 \pm 50.55$ & 0.299 \\
\hline Total cholesterol & $158.50 \pm 39.64$ & $151.24 \pm 35.98$ & $158.80 \pm 41.45$ & $137.02 \pm 29.86$ & $184.55 \pm 39.64$ & 0.081 \\
\hline LDL & $91.97 \pm 38.25$ & $79.54 \pm 32.92$ & $90.30 \pm 34.31$ & $86.48 \pm 26.42$ & $110.89 \pm 49.07$ & 0.326 \\
\hline HDL & $40.68 \pm 11.06$ & $41.20 \pm 13.08$ & $38.90 \pm 5.74$ & $39.98 \pm 11.48$ & $42.78 \pm 13.07$ & 0.889 \\
\hline Triglycerides & $154.33 \pm 78.71$ & $160.33 \pm 90.65$ & $157.90 \pm 92.47$ & $124.63 \pm 43.56$ & $170.78 \pm 79.79$ & 0.676 \\
\hline Leptin (ng/ml) & $40.34 \pm 24.67$ & $24.64 \pm 12.47$ & $46.96 \pm 29.06$ & $44.54 \pm 25.75$ & $44.97 \pm 24.55$ & 0.178 \\
\hline $\mathrm{CRP}(\mu \mathrm{g} / \mathrm{ml})$ & $4.06 \pm 2.12$ & $3.03 \pm 1.40$ & $4.16 \pm 2.28$ & $4.20 \pm 2.72$ & $4.83 \pm 1.85$ & 0.347 \\
\hline
\end{tabular}

The data are presented as the mean \pm standard deviation. BMI, body mass index; DEXA, dual-energy X-ray absorptiometry; LDL, low density lipoprotein; HDL, high density lipoprotein; CRP, C-reactive protein.

Table II. Correlational matrix of the key variables of interest.

\begin{tabular}{|c|c|c|c|c|c|c|c|c|}
\hline Characteristic & BMI & Age & Gender & $\begin{array}{c}\text { Waist } \\
\text { circumference }\end{array}$ & $\begin{array}{l}\text { Percent } \\
\text { body fat }\end{array}$ & Cholesterol & Leptin & CRP \\
\hline \multicolumn{9}{|l|}{ BMI } \\
\hline Age & $-0.521^{\mathrm{a}}$ & & & & & & & \\
\hline Gender & -0.216 & 0.262 & & & & & & \\
\hline Waist circumference & $0.667^{\mathrm{a}}$ & -0.199 & -0.001 & & & & & \\
\hline Percentage body fat & $0.692^{\mathrm{a}}$ & -0.289 & $-0.610^{*}$ & $0.520^{\mathrm{a}}$ & & & & \\
\hline Cholesterol & 0.300 & -0.194 & -0.034 & $0.363^{\mathrm{b}}$ & 0.118 & & & \\
\hline Leptin & 0.246 & 0.074 & -0.113 & 0.257 & 0.173 & 0.264 & & \\
\hline CRP & $0.340^{\mathrm{b}}$ & -0.265 & $-0.382^{b}$ & 0.205 & $0.426^{\mathrm{b}}$ & 0.195 & $0.525^{\mathrm{a}}$ & \\
\hline
\end{tabular}

${ }^{\mathrm{a}} \mathrm{P}<0.01$ (2-tailed) and ${ }^{\mathrm{b}} \mathrm{P}<0.05$ (2-tailed). BMI, body mass index; CRP, C-reactive protein.

Table III. Gender differences between CRP, leptin and percentage body fat.

\begin{tabular}{lcccr}
\hline Characteristic & $\begin{array}{c}\text { All participants } \\
(\mathrm{n}=36)\end{array}$ & $\begin{array}{c}\text { Males } \\
(\mathrm{n}=28)\end{array}$ & $\begin{array}{c}\text { Females } \\
(\mathrm{n}=8)\end{array}$ & P-value \\
\hline $\mathrm{CRP}(\mu \mathrm{g} / \mathrm{ml})$ & $4.06 \pm 2.12$ & $3.63 \pm 2.13$ & $5.55 \pm 1.29$ & 0.022 \\
Leptin $(\mathrm{ng} / \mathrm{ml})$ & $40.34 \pm 24.67$ & $38.87 \pm 24.97$ & $45.49 \pm 24.47$ & 0.511 \\
Total \% fat & $36.88 \pm 6.98$ & $34.59 \pm 5.87$ & $44.58 \pm 4.53$ & $<0.001$ \\
\hline
\end{tabular}

CRP, C-reactive protein.

the level of obesity increased (Table IV). In the most obese patients (BMI, 40.3-61.2), CRP and leptin were significantly higher compared with the least obese patients (BMI, 28.6-32.4).

\section{Discussion}

To the best of our knowledge, the present study is the first to examine the association between CRP, leptin and adiposity and other cardiovascular risk factors in overweight/obese patients with HF, DM and/or MS. The moderately strong association between CRP and adiposity observed in the present study is in accordance with a previous study that linked adiposity with a chronic state of inflammation, which may be involved in the development of multiple chronic illnesses, including cardiovascular disease and MS (29). Furthermore, inflammation in the presence of obesity is hypothesized to arise primarily in adipose tissue due to alterations in metabolic homeostasis leading to increased cytokine production and the activation of inflammatory signaling pathways in the body (30). Therefore, the importance of weight loss, accompanied by reductions 
Table IV. Comparison of CRP and leptin levels in the lowest and highest BMI quartiles.

\begin{tabular}{lcccc}
\hline & & \multicolumn{2}{c}{ BMI quartile } \\
\cline { 3 - 5 } Characteristic & $\begin{array}{c}\text { All participants } \\
(\mathrm{n}=36)\end{array}$ & $\begin{array}{c}\text { (i) } 28.6-32.4 \\
(\mathrm{n}=9)\end{array}$ & $\begin{array}{c}\text { (iv) } 40.3-61.2 \\
(\mathrm{n}=9)\end{array}$ \\
\hline $\mathrm{CRP}(\mu \mathrm{g} / \mathrm{ml})$ & $4.06 \pm 2.12$ & $3.03 \pm 1.40$ & $4.83 \pm 1.85$ & 0.033 \\
Leptin $(\mathrm{ng} / \mathrm{ml})$ & $40.34 \pm 24.67$ & $24.64 \pm 12.47$ & $44.97 \pm 24.55$ & 0.042 \\
\hline
\end{tabular}

BMI, body mass index; CRP, C-reactive protein.

in percentage body fat, requires further investigation in this population to evaluate the usefulness of CRP as a prognostic marker of inflammation and disease state in a subgroup of overweight/obese patients with HF, DM and/or MS.

In the present study, a statistically significant correlation between CRP and leptin was identified, independent of BMI in the present study population of overweight/obese patients with $\mathrm{HF}$, and this has also been confirmed in a number of other patient populations and healthy adults (20-25). The marked increase revealed in the concentration of these markers as the level of adiposity increased provides further support for an association between these inflammatory biomarkers and obesity. Whilst studies investigating the association between CRP and adiposity are widespread in various populations $(8-11,29)$, the association between leptin and obesity appears to be more complex. Leptin was previously considered to only be involved in energy balance and satiety. However, it has now been demonstrated that leptin receptors are located throughout the body, including the heart, suggesting that it is also involved in the regulation of other processes (31). Recently, it has been suggested that leptin may act as a cardiac hypertrophic factor linked to obesity and that concurrent elevated leptin levels are associated with cardiovascular risk, particularly in patients with HF (32).

The mechanisms linking CRP with leptin in different disease models is not well understood. Since CRP synthesis is considered to be regulated by IL-6 (7), and since leptin secretion from human adipose tissue also stimulates the production of various cytokines (including IL-6), it has been hypothesized that leptin may regulate CRP production $(20,21)$. In obesity, CRP has also been postulated to be involved in the development of leptin resistance (26-28). The clinical significance of the association between CRP and leptin, and the possible additive effects of these measures of inflammation/immunomodulation as they are associated with an increased cardiovascular risk, warrants further investigation.

The results from the present study demonstrated that levels of CRP were significantly higher in females compared with males; however, differences in leptin levels between males and females were not observed. It was also found that females had a greater percentage body fat compared with males. A study of $\sim 2,750$ individuals, aged between 30 and 65 years $(>50 \%$ female) found that CRP levels were almost twice as high in females compared with males (3.3 vs. $1.8 \mathrm{mg} / \mathrm{l}$; $\mathrm{P}<0.05)$ (33). In a recent study Khera et al (34) investigated gender differences in the association between CRP and body fat. Previous studies have also revealed that the quantity and distribution of body fat affects CRP to a greater extent in females compared with males. Therefore, the results from the present study are in accordance with the hypothesis that adiposity, associated with subclinical inflammation, may be of particular importance in females. The question remains, however, as to the value of CRP in assessing the risk of cardiovascular disease in males compared with females. While CRP levels are higher in females compared with males, males develop heart disease more frequently and have a higher positive correlation with CRP compared with females $(35,36)$. Gender differences were evaluated in the National Health and Nutrition Examination Survey, and it was demonstrated that, while males with elevated levels of CRP (>3.0 mg/dl) had increased cardiovascular mortality and all-cause mortality hazards (defined by hazard ratios or HR), this difference was not observed in females, leading to the conclusion that there is a requirement to tailor recommendations on diagnostic and prognostic use of CRP based on gender (37). Future investigation is required to illustrate the differences in gender and CRP as it is associated with obesity in females and males to further clarify the importance of this inflammatory marker in cardiovascular and associated risk factors. The findings of the present study regarding the correlation of CRP with leptin in overweight/obese patients with HF, DM and/or MS, and the lack of gender differences in the levels of leptin may indicate the potential effectiveness of concurrent use of these biomarkers in prognosis and designing of weight-loss interventions to affect clinical outcomes in this patient population.

The present study was limited by the number of participants enrolled and the fewer numbers of females compared with males. Furthermore, there is always a limitation in analyzing multiple factors in biological systems (e.g. leptin, CRP and obesity) due to the adjustments that have to be made for common disease pathways. Finally, analysis of the current diet and physical activity of each participant may potentially alter the risk estimates used in the present study. In future, a larger sample size is required and the effect of weight loss regimens need to be evaluated to further reveal the link between inflammation, adiposity and adipokines, and their association with risk factors and outcome in overweight/obese patients with HF, DM and/or MS.

\section{Acknowledgements}

The authors would like to acknowledge funding from the National Heart, Lung and Blood Institute (1R01HL093466-01) and the University of California, Los Angeles (UCLA), 
Resource Centers for Minority Aging Research/Center for Health Improvement of Minority Elderly (RCMAR/CHIME) under the National Institute in Aging (P30-AG02-1684, PI, C. Mangione). The content is solely the responsibility of the authors and does not necessarily represent the official views of the National Heart, Lung and Blood Institute-National Institutes of Health or the National Institute on Aging.

The authors would also like to acknowledge support from the University of California, Irvine (UCI) Institute for Clinical Translational Science (ICTS) and UCLA Clinical and Translational Science Institute (CTSI). The project was supported by the National Institutes of Health/National Center for Research Resources and the National Center for Advancing Translational Sciences (NCATS), through UCI ICTS (grant no. UL1 TR000153) and by NIH/NCATS, UCLA CTSI (grant no. UL1TR000124). The content is solely the responsibility of the authors and does not necessarily represent the official views of the NIH.

\section{References}

1. Motie M, Evangelista LS, Horwich TB, et al: Pro-HEART - a randomized clinical trial to test the effectiveness of a high protein diet targeting obese individuals with heart failure: rationale, design and baseline characteristics. Contemp Clin Trials 36 371-381, 2013.

2. Horwich TB, Fonarow GC, Hamilton MA, MacLellan WR, Woo MA and Tillisch JH: The relationship between obesity and mortality in patients with heart failure. J Am Coll Cardiol 38: 789-795, 2001.

3. Davos CH, Doehner W, Rauchhaus M, Cicoira M, Francis D, Coats AJ, Clark AL and Anker SD: Body mass and survival in patients with chronic heart failure without cachexia: the importance of obesity. J Card Fail 9: 29-35, 2003.

4. Lissin LW, Gauri AJ, Froelicher VF, Ghayoumi A, Myers J and Giacommini J: The prognostic value of body mass index and standard exercise testing in male veterans with congestive heart failure. J Card Fail 8: 206-215, 2002.

5. Mosterd A, Cost B, Hoes AW, et al: The prognosis of heart failure in the general population: The Rotterdam Study. Eur Heart J 22: 1318-1327, 2001.

6. Anker SD, Negassa A, Coats AJ, Afzal A, Poole-Wilson PA, Cohn JN and Yusuj S: Prognostic importance of weight loss in chronic heart failure and the effect of treatment with angiotensin-converting-enzyme inhibitors: an observational study. Lancet 361: 1077-1083, 2003.

7. Castell JV, Gómez-Lechión M, David M, et al: Acute phase response of human hepatocyte: regulation of acute-phase protein synthesis by interleukin-6. Hepatology 12: 1179-1186, 1990.

8. Ridker M, Buring JE, Cook NR and Rifai N: C-reactive protein, the metabolic syndrome, and risk of incident cardiovascular events: an 8-year follow-up of 14719 initially healthy American women. Circulation 107: 391-397, 2003.

9. Koenig W, Sund M, Fröhlich M, Fischer HG, Löwel H, Döring A, Hutchinson WL and Pepys MB: C-Reactive protein, a sensitive marker of inflammation, predicts future risk of coronary heart disease in initially healthy middle-aged men: results from the MONICA (Monitoring Trends and Determinants in Cardiovascular Disease) Ausburg Cohort Study, 1984 to 1992. Circulation 99: 237-242, 1999.

10. Tracy RP, Lemaitre RN, Psaty BM, Ives DG, Evans RW, Cushman M, Meilahn EN and Kuller LH: Relationship of C-reactive protein to cardiovascular disease in the elderly: results from the Cardiovascular Health Study and the Rural Health Promotion Project. Arterioscler Thromb Vasc Biol 17: 1121-1127, 1997.

11. Rutter MK, Meigs JB, Sullivan LM, D'Agostino RB Sr and Wilson PW: C-reactive protein, the metabolic syndrome, and prediction of cardiovascular events in the Framingham Offspring Study. Circulation 110: 380-385, 2004.

12. Visser M, Bouter LM, McQuillan GM, Wener MH and Harris TB: Elevated C-reactive protein levels in overweight and obese adults. JAMA 282: 2131-2135, 1999.
13. Brennan AM and Mantzoros CS: Drug insight: the role of leptin in human physiology and pathophysiology - emerging clinical applications. Nat Clin Pract Endocrinol Metab 2: 318-327, 2006.

14. Halaas JL, Gajiwala KS, Maffei M, Cohen SL, Chait BT, Rabinowitz D, Lallone RL, Burley SK and Friedman JM: Weight-reducing effects of the plasma protein encoded by the obese gene. Science 269: 543-546, 1995.

15. Franks PW, Brage S, Luan J, Ekelund U, Rahman M, Farooqi IS Halsall I, O'Rahilly S and Wareham NJ: Leptin predicts a worsening of the features of the metabolic syndrome independently of obesity. Obes Res 13: 1476-1484, 2005.

16. Wallace AM, McMahon AD, Packard CJ, Kelly A, Shepherd J, Gaw A and Sattar N: Plasma leptin and the risk of cardiovascular disease in the west of Scotland coronary prevention study (WOSCOPS). Circulation 104: 3052-3056, 2001.

17. Sierra-Johnson J, Romero-Corral A, Lopez-Jimenez F, Gami AS Sert Kuniyoshi FH, Wolk R and Somers VK: Relation of increased leptin concentrations to history of myocardial infarction and stroke in the US population. Am J Cardiol 100: 234-239, 2007.

18. Söderberg S, Ahrén B, Jansson JH, Johnson O, Hallmans G, Asplund $\mathrm{K}$ and Olsson T: Leptin is associated with increased risk of myocardial infarction. J Intern Med 246: 409-418, 1999.

19. Singh P, Hoffmann M, Wolk R, Shamsuzzaman AS and Somers VK: Leptin induces C-reactive protein expression in vascular endothelial cells. Arterioscler Thromb Vasc Biol 27: e302-e307, 2007.

20. Chiu FH, Chuang CH, Li WC, Weng YM, Fann WC, Lo HY, Sun C and Wang SH: The association of leptin and C-reactive protein with the cardiovascular risk factors and metabolic syndrome score in Taiwanese adults. Cardiovasc Diabetol 11: 40, 2012.

21. Shamsuzzaman AS, Winnicki M, Wolk R, Svatikova A, Phillips BG, Davison DE, Berger PB and Somers VK: Independent association between plasma leptin and C-reactive protein in healthy humans. Circulation 109: 2181-2185, 2004.

22. Viikari LA, Huupponen RK, Viikari JS, Marniemi J, Eklund C, Hurme M, Lhetimäki T, Kivimäki $M$ and Raitakari OT: Relationship between leptin and C-reactive protein in young Finnish adults. J Clin Endocrinol Metab 92: 4753-4758, 2007.

23. Yanagawa T, Taniguchi A, Fukushima M, Nakai Y, Nagasaka S, Ohgushi M, Matsumotoe K, Kuroea A, Ohyaa M and Seinoa Y: Leptin, triglycerides, and interleukin 6 are independently associated with C-reactive protein in Japanese type 2 diabetic patients. Diabetes Res Clin Pract 75: 2-6, 2007.

24. Kazumi T, Kawaguchi A, Hirano T and Yoshino G: C-reactive protein in young, apparently healthy men: associations with serum leptin, QTc interval, and high-density lipoprotein-cholesterol. Metabolism 52: 1113-1116, 2003.

25. Ble A, Windham BG, Bandinelli S, Taub DD, Volpato S, Bartali B, Tracy RP, Guralnik JM and Ferrucci L: Relation of plasma leptin to C-reactive protein in older adults (from the Invecchiare nel Chianti study). Am J Cardiol 96: 991-995, 2005.

26. Chen K, Li F, Li J, Cai H, Strom S, Bisello A, Kelley DE, Friedman-Einat M, Skibinski GA, McCrory MA, Szalai AJ and Zhao AZ: Induction of leptin resistance through direct interaction of C-reactive protein with leptin. Nat Med 12: 425-432, 2006.

27. Myers MG Jr, Leibel RL, Seeley RJ and Schwartx MW: Obesity and leptin resistance: distinguishing cause from effect. Trends Endocrinol Metab 21: 643-651, 2010.

28. Hribal ML, Fiorentino TV and Sesti G: Role of C reactive protein (CRP) in leptin resistance. Curr Pharm Des; May 14, 2013 (Epub ahead of print).

29. Nguyen XM, Lane J, Smith BR and Nguyen NT: Changes in inflammatory biomarkers across weight classes in a representative US population: a link between obesity and inflammation. J Gastrointest Surg 13: 1205-1212, 2009.

30. Yudkin JS, Stehouwer CD, Emeis JJ and Coppack SW: C-reactive protein in healthy subjects: associations with obesity, insulin resistance, and endothelial dysfunction: a potential role for cytokines originating from adipose tissue? Arterioscler Thromb Vasc Biol 19: 972-978, 1999.

31. Kowalska I: Role of adipose tissue in the development of vascular complications in type 2 diabetes mellitus. Diabetes Res Clin Pract 78: S14-S22, 2007.

32. Karmazyn $\mathbf{M}$ and Rajapurohitam V: Leptin as a cardiac pro-hypertrophic factor and its potential role in the development of heart failure. Curr Pharm Des; May 14, 2013 (Epub ahead of print).

33. Khera A, McGuire DK, Murphy SA, Stanek HG, Das SR, Vongpatanasin W, Wians FH Jr, Grundy SM and de Lemos JA: Race and gender differences in C-reactive protein levels. J Am Coll Cardiol 46: 464-469, 2005. 
34. Khera A, Vega GL, Das SR, Ayers C, McGuire DK, Grundy SM and de Lemos JA: Sex differences in the relationship between C-reactive protein and body fat. J Clin Endocrinol Metab 94: 3251-3258, 2009.

35. Pai JK, Pischon T, Ma J, Manson JE, Hankinson SE, Joshipura K, Curhan GC, Rifai N, Cannuscio CC, Stampfer MJ and Rimm EB: Inflammatory markers and the risk of coronary heart disease in men and women. N Engl J Med 351: 2599-2610, 2004.
36. Cushman M, Arnold AM, Psaty BM, Manolio TA, Kuller LH, Burke GL, Polak JF and Tracy RP: C-reactive protein and the 10 -year incidence of coronary heart disease in older men and women: the cardiovascular health study. Circulation 112: 25-31, 2005.

37. Doran B, Zhu W and Muennig P: Gender differences in cardiovascular mortality by C-reactive protein level in the United States: evidence from the National Health and Nutrition Examination Survey III. Am Heart J 166: 45-51, 2013. 